\title{
La jurisprudencia de la Corte Interamericana de Derechos Humanos como fuente de derecho. Una revisión de la doctrina del "examen de convencionalidad"
}

\author{
Sergio Fuenzalida Bascuñán*
}

\begin{abstract}
RESUMEN
La doctrina internacionalista nos enseña que las sentencias dictadas por los tribunales internacionales solo constituyen fuente auxiliar de derecho internacional y solo tienen efectos para las partes en litigio y respecto del caso que ha sido decidido. La Corte Interamericana de Derechos Humanos (CIDH) ha dispuesto que los Estados partes deben realizar un control de convencionalidad que contraste las normas locales con la jurisprudencia desarrollada por ella. El control de convencionalidad supone instituir las decisiones de la CIDH como fuente de derecho interno, bajo una aplicación directa y restringiendo el campo de decisión soberana de los países. Para que el control de convencionalidad pueda consolidarse en el sistema interamericano de derechos bumanos es pertinente contar con una expresa autorización constitucional de los países miembros e incorporar de un modo diferenciado la doctrina del margen de apreciación nacional. Asimismo, es conveniente que la CIDH mediante mecanismos de reparación inéditos pueda explorar distintas formas de diálogo interinstitucional con los poderes locales.
\end{abstract}

Derecho internacional - fuentes de derecho - control de convencionalidad - Corte Interamericana de Derechos Humanos

The jurisprudence of the Inter-American Court of Human Rights as a source of law. A review of the doctrine of "examination of compliance"

\section{Abstract}

The international law doctrine affirms that the judgments of international courts are only auxiliary source of international law producing effects on parties and in respect of the case decided only. The Inter-American Court of Human Rights has ruled that member States should conduct a review for compliance (control de convencionalidad) contrasting local regulations with

* Magister en Derecho Constitucional. Profesor de Derecho, Universidad Central de Chile. Correo electrónico: sfuenzalidab@ucentral.cl

Artículo recibido el 27 de diciembre de 2013 y aceptado para su publicación el 27 de marzo de 2015. 
the Court case law. This review implies to understand the decisions of the IACHR as a source of domestic law, with direct applicability and consequentially limiting the scope of sovereign decision of the member States. For the consolidation of this review in the inter-American buman rights system, it is appropriate to have an express constitutional authorization of the member States and include the resource to the doctrine of the margin of national appreciation. It would be appropriate for the IACHR, using unprecedented mechanisms of reparation, to explore different forms of interagency dialogue with local authorities.

International Law - sources of law - Conventionality control - Inter-American Court of Human Rights

\section{LAS SENTENCIAS INTERNACIONALES COMO FUENTE DEL DERECHO} INTERNACIONAL Y EL “CONTROL DE CONVENCIONALIDAD” DE LA CORTE INTERAMERICANA DE Derechos Humanos

$\mathrm{E}$ xiste un marcado contraste entre lo que postulan los profesores de derecho internacional acerca de la posición que ocupan las sentencias dictadas por los tribunales internacionales entre las fuentes del derecho y lo postulado por la Corte Interamericana de Derechos Humanos (en adelante CIDH) a propósito del alcance de sus decisiones. Siguiendo el tenor del artículo 38 del Estatuto de la Corte Internacional de Justicia los autores internacionalistas atribuyen a las sentencias solo un valor meramente auxiliar, en cambio la $\mathrm{CIDH}$ ha venido sosteniendo una posición diversa al menos en relación con el valor de sus sentencias como fuente de derecho a nivel interno. Veamos a continuación la posición de ambas partes.

\subsection{Las decisiones judiciales y las fuentes de derecho internacional, según la doctrina del derecho internacional}

Por regla general, los autores internacionalistas al momento de analizar las fuentes del derecho internacional recurren al artículo 38 del Estatuto de la Corte Internacional de Justicia para explicar los alcances secundarios que tendrían las decisiones judiciales en la creación de este tipo de derecho.

Este artículo dispone que "La Corte, cuya función es decidir conforme al derecho internacional las controversias que le sean sometidas, deberá aplicar: a) las convenciones internacionales, sean generales o particulares, que establecen reglas expresamente reconocidas por los Estados litigantes; b) la costumbre internacional como prueba de una práctica generalmente aceptada como derecho; c) los principios generales de derecho reconocidos por las naciones civilizadas". Asmismo, pero solo como "medio auxiliar para la determinación de las reglas de derecho", puede utilizar "las decisiones judiciales y las doctrinas de los publicistas de mayor competencia de las distintas naciones". Lo que es sin perjuicio de lo dispuesto en el artículo 59 que indica que "La decisión de la Corte [Internacional de Justicia] no es obligatoria sino para las partes en litigio y respecto del caso que ha sido decidido". 
Basado en este artículo, y sin perjuicio de reconocer la existencia de otras fuentes del derecho internacional no incluidas en la norma referida ${ }^{1}$, en lo tocante a las decisiones judiciales la doctrina internacionalista está conteste en que ellas solo sirven "como medio auxiliar para la determinación de las reglas de derecho”. Esto significa, tal y como lo expresa el profesor Llanos Mansilla, que "la jurisprudencia es un medio auxiliar, no una fuente independiente, esto es, sirve para confirmar una norma que se cree existente y que proviene de otras fuentes. Un fallo no puede apoyarse solo en precedentes. Crea reglas particulares, no normas generales de Derecho" ${ }^{2}$.

Para Julio Barboza, por su parte, de conformidad con el artículo 38 del Estatuto de la CIJ, la jurisprudencia y la doctrina no tendrían el carácter de "fuentes autónomas -esto es, productoras de normas jusinternacionales-, sino de fuentes a las que el Tribunal puede recurrir para mejor discernir los perfiles de normas provistas por las fuentes principales". La jurisprudencia tendría así solo una función "especificadora [...] estos es, de establecer especies subordinadas a los géneros legales”. Ello significaría "que la doctrina del precedente obligatorio, conocida en el comon law anglosajón como stare decisis, no tiene vigencia en el derecho de gentes", por lo que "la jurisprudencia no crea normas generales de aplicación obligatoria a otros casos, sino solo una norma individual que regla los derechos de las partes en el caso particular". Ello aun cuando el apego de la CIJ de sus propios precedentes sea considerable, según el autor argentino ${ }^{3}$.

Por su parte, el autor español Fernando Mariño enseña algo muy parecido. Manifiesta que la "jurisprudencia y doctrina tienen una función subsidiaria que se cumple después de que se hayan considerado las normas del Derecho Internacional positivo y únicamente con la finalidad de perfilar su sentido o de construirlo”. Además -agrega el Mariño- su ámbito de aplicación es restringido: "debe señalarse ante todo que una sentencia válida de un tribunal internacional (arbitral o judicial) es un hecho jurídico normativo que soluciona una controversia internacional por medio de la creación de normas obligatorias pero únicamente para los sujetos de Derecho Internacional, partes en un litigio contencioso y con relación al caso objeto de la decisión [...]”. Ello no obsta, empero, a que algunas sentencias por los temas que abordan, por la calidad de sus razonamientos y por la autoridad de los juristas que integran el tribunal, pueden influir significativamente en el Derecho Internacional; sin embargo "juzgar no es crear Derecho de aplicación general” -señala el autor-. Ni siquiera "la práctica consistente en la repetición

\footnotetext{
${ }^{1}$ Por ejemplo, para el autor mexicano Manuel Becerra durante todo el siglo XX la postura dominante identificó las fuentes del derecho con lo dispuesto en el artículo 38 del CIJ, en una suerte de sacralización del artículo referido, aun cuando la realidad internacional ha sobrepasado con creces los estrechos márgenes de lo ahí dispuesto. Becerra, M., La recepción del derecho internacional en el derecho interno, Universidad Nacional Autónoma de México, México D.F., 2006, pp. 1 y 2.

${ }^{2}$ Llanos, H., Teoría y Práctica del Derecho Internacional Público, Tomo I, Editorial Jurídica de Chile, Santiago, 2009, pp. 573.

${ }^{3}$ Barboza, J., Derecho Internacional Público, Víctor P. de Zavalía, Argentina, 2008, pp. 150 a 152. Para Manuel Becerra, por su parte, en su Derecho Internacional Público, de 1991, nos decía que "las decisiones judiciales y la doctrina son solamente medios auxiliares; no son una verdadera fuente, ya que una sentencia no puede basarse solo en decisiones judiciales anteriores".
} 
de sentencias internacionales aplicadoras de idéntica norma, de modo ininterrumpido, general y constante, es por sí sola suficiente para originar una costumbre internacional". Se requeriría para esto último "la práctica de los Estados u otros sujetos" ${ }^{4}$.

Con todo, para el autor británico Malcom Shaw la jurisprudencia puede cumplir un rol de mayor significancia en el derecho internacional. Nos dice que las sentencias "[a]unque son, en palabras del artículo 38, para ser utilizadas como medio subsidiario para la determinación de normas de derecho y no como una fuente real del derecho, las decisiones judiciales pueden ser de gran importancia" 5 . Igual que el juez inglés que crea derecho en el proceso de interpretación, el juez internacional hace más que meramente "determinar" las fuentes del derecho internacional. La práctica común por parte de la CIJ es examinar con considerable atención su propia jurisprudencia, y solo por excepción se aparta de ella. Por lo demás, muchas de las decisiones de la CIJ, como también las sentencias dictadas en casos de arbitraje internacional y las dictadas por otros tribunales internacionales, han servido como fuente decisiva para la creación de normas de derecho internacional ${ }^{6}$.

Ahora veamos cómo la Corte Interamericana ha entendido el valor jurídico de sus decisiones judiciales en relación con la soberanía interna de los Estados partes de la Convención Americana de Derechos Humanos.

\subsection{La doctrina del "control de convencionalidad" por la Corte Interamericana de Derechos Humanos. La jurisprudencia internacional como fuente de derecho}

Distanciándose de los que enseñan la doctrina internacional, la CIDH, por medio de lo que ha entendido como "control de convencionalidad", ha venido sosteniendo que los tribunales nacionales deben contrastar la normativa local con la Convención Americana de Derechos Humanos, de modo que de existir una contradicción normativa se debe preferir la normativa internacional. Control que debe basarse en lo dispuesto en la Convención Americana, pero además - lo que interesa mayormente aquí- en "la interpretación que del mismo [Pacto] ha hecho la Corte Interamericana [en] sus resoluciones, como intérprete última de la Convención Americana"

Así, en el caso Almonacid Arellano vs. Chile dispuso lo que sigue:

${ }^{4}$ Mariño, F., Derecho Internacional Público, Parte General, Trotta, Madrid, 1999, pp. 379 y 380.

${ }^{5}$ Saw, M., International Law, VI Edición, Cambridge, 2008, pp. 109 y 110. Traducción propia, el texto en inglés es el siguiente: (a)lthough these are, in the words of article 38, to be utilised as a subsidiary means for the determination of rules of law rather than as an actual source of law, judicial decisions can be of immense importance.

${ }^{6}$ Esto también lo señala de alguna manera Llanos Mansilla. Entrega varios ejemplos de cómo las decisiones de tribunales arbitrales, como también los tribunales de Nuremberg y Tokio, fueron incorporando principios y aportes al derecho internacional, e incluso en el caso de los últimos tribunales mencionados se crearon nuevos delitos. Llanos, H., op. cit., pp. 573 y 574.

${ }^{7}$ CIDH. Caso Almonacid Arellano vs. Chile, p. 124. 
"La Corte es consciente que los jueces y tribunales internos están sujetos al imperio de la ley y, por ello, están obligados a aplicar las disposiciones vigentes en el ordenamiento jurídico. Pero cuando un Estado ha ratificado un tratado internacional como la Convención Americana, sus jueces, como parte del aparato del Estado, también están sometidos a ella, lo que les obliga a velar porque los efectos de las disposiciones de la Convención no se vean mermadas por la aplicación de leyes contrarias a su objeto y fin, y que desde un inicio carecen de efectos jurídicos. En otras palabras, el Poder Judicial debe ejercer una especie de 'control de convencionalidad' entre las normas jurídicas internas que aplican en los casos concretos y la Convención Americana sobre Derechos Humanos. En esta tarea, el Poder Judicial debe tener en cuenta no solamente el tratado, sino también la interpretación que del mismo ha hecho la Corte Interamericana, intérprete última de la Convención Americana".

Esta primera expresión de la doctrina del control de convencionalidad luego ha sido ampliada significativamente. La Corte ha dispuesto que el examen de convencionalidad debe realizarse de oficio por la magistratura local, y dentro del ámbito de competencias y de las regulaciones procesales correspondientes ${ }^{9}$. Asimismo, que dicho control compete a cualquier juez o tribunal que ejerza funciones de jurisdicción ${ }^{10}$, y, finalmente, que el control de convencionalidad atañe no solo a las autoridades jurisdiccionales, sino que a toda autoridad pública ${ }^{11}$.

En relación con esto último, en cuanto a que la obligación de convencionalidad alcanzaría a cualquier expresión del poder estatal, la Corte inclusive ha sostenido que esta doctrina se aplica cuando es la propia soberanía popular la que se ha expresado directamente ${ }^{12}$. Así lo indicó en el caso Gelman vs. Uruguay, que declaró que carecía de efectos jurídicos una ley, aun cuando ella había sido dictada por el Parlamento uruguayo

${ }^{8}$ Ibid.

${ }^{9}$ CIDH. Trabajadores Cesados del Congreso (Aguado Alfaro y otros) vs. Perú, párr. 128.

${ }^{10} \mathrm{CIDH}$, Cabrera García y Montiel Flores vs. México, párr. 225.

${ }^{11}$ Respecto de la evolución de la doctrina del examen de convencionalidad, Cfr. Nash, C., "Control de Convencionalidad. Precisiones conceptuales a la luz de la jurisprudencia de la Corte Interamericana de Derechos Humanos", en El diálogo transjudicial de los Tribunales Constitucionales entre sí y con las Cortes Internacionales de Derechos Humanos, en Nogueira H. (coord.), Librotecnia, Santiago, 2012, pp. 366 a 371.

${ }^{12} \mathrm{La} \mathrm{CIDH}$ en ese caso declaró que carecía de efectos jurídicos una ley dictada por el Parlamento uruguayo y que había sorteado dos intentos de ser derogada y anulada mediante procedimientos de ejercicio directo de la democracia. La Corte, a la letra, señaló que "[1]a legitimación democrática de determinados hechos o actos en una sociedad está limitada por las normas y obligaciones internacionales de protección de los derechos humanos reconocidos en tratados como la Convención Americana, de modo que la existencia de un verdadero régimen democrático está determinada por sus características tanto formales como sustanciales, por lo que, particularmente en casos de graves violaciones a las normas del Derecho Internacional de los Derechos, la protección de los derechos humanos constituye un límite infranqueable a la regla de mayorías, es decir, a la esfera de lo 'susceptible de ser decidido' por parte de las mayorías en instancias democráticas, en las cuales también debe primar un 'control de convencionalidad' (supra párr. 193), que es función y tarea de cualquier autoridad pública y no solo del Poder Judicial”. CIDH, Caso Gelman vs. Uruguay, párr. 239. 
y había sorteado dos intentos de ser derogada y anulada mediante procedimientos de ejercicio directo de la democracia ${ }^{13}$.

\subsection{Características e implicancias del control de convencionalidad}

Néstor Sagüés ha caracterizado el mecanismo de control de convencionalidad de un modo en que aparece de manifiesto toda la novedad del instituto. Ha dicho que: “a) es profundamente importante advertir que la Corte Interamericana destaca que el material controlante no consiste exclusivamente en las normas del Pacto, sino también en la interpretación dada a esas reglas por la Corte Interamericana. "Almonacid Arellano, además, no distingue entre interpretaciones vertidas en sentencias (parte resolutiva y fundamentos), o en opiniones consultivas. En otras palabras, el material normativo controlante está conformado por las cláusulas del Pacto de San José de Costa Rica, más la exégesis que de ellas ha hecho la Corte Interamericana”. Para el autor de la Universidad de Buenos Aires "de hecho, esta tesis importa una interpretación mutativa por adición realizada sobre el Pacto por la Corte Interamericana, en su condición de intérprete definitiva del mismo (Art. 67). El tribunal ha agregado algo al contenido inicial del Pacto, aunque el texto literal de este no ha variado. Así, un Estado puede verse obligado por la doctrina establecida por la Corte Interamericana de Derechos Humanos, en una causa en la que él no ha sido parte, ni obviamente tenido oportunidad para alegar en pro de una interpretación diferente a la formulada en aquel expediente. Paralelamente, la interpretación formulada por la Corte Interamericana va a tener de hecho el mismo valor que la letra del Pacto, e incluso será superior a la redacción de este, porque como intérprete final del mismo fija la superficie y el alcance de sus cláusulas escritas".

Ello implica instalar en el sistema jurídico latinoamericano una institución en principio ajena al sistema jurídico de derecho continental. Nos dice Sagüés que: "en conclusión, la Corte Interamericana de Derechos Humanos, merced a la doctrina del control de convencionalidad, ha afirmado como obligatoria una tesis semejante, de algún modo, al stare decisis, o valor del precedente estadounidense de su Corte Suprema de Justicia, doctrina creada en aquel país también sin un texto constitucional expreso que la haya sostenido. O si se prefiere, asume los roles de una Corte de Casación supranacional en derechos humanos, en aras de uniformar la interpretación de los derechos de esa índole emergentes del Pacto de San José de Costa Rica. Y ello importa, inexorablemente, una sensible reducción de las facultades de los jueces nacionales en materia de control de constitucionalidad y de interpretación de los derechos personales. De aquí en más ya no son libres de descifrar esos derechos a su independiente leal saber y entender, sino que deben comprenderlos con el significado que hasta ahora les ha dado, y les dará en el futuro la Corte Interamericana. Asimismo, tendrán que 'leer' los derechos

${ }^{13}$ Nash, C., op. cit, pp. 367 a 371. 
constitucionales locales en consonancia con esas directrices, como puntualizamos infra, en el parágrafo $\mathrm{X}(\ldots)^{\prime 14}$.

De este modo, el control de convencionalidad que dispone la Corte Interamericana supone la afirmación de un orden jurídico supranacional, y junto a ello la existencia de un tribunal de las mismas características con competencia para sancionar a los Estados partes y fijarle internamente los estándares de derechos humanos a los que deben sujetarse. Incluso declarando inválidas las normas de su derecho interno que no se adecuen a las normas internacionales, ordenando asimismo su inaplicabilidad a futuro. Los países que han suscrito el Pacto de San José de Costa Rica y aceptado la jurisdicción de la $\mathrm{CIDH}$, se someterían de este modo a un cuerpo normativo vinculante, formado no solo por las cláusulas del convenio, sino por las decisiones de la $\mathrm{CIDH}$, que obliga directa e internamente, y que consagra derechos humanos inmunes a la soberanía ${ }^{15}$. Derechos que configuran un orden público común entre los Estados partes ${ }^{16}$ que no es posible volver a "nacionalizar"17.

Por eso ha sostenido un autor que "la Convención Americana de Derechos Humanos es norma de normas" en la Organización de Estados Americanos y "la Corte Interamericana se establece como auténtico guardián e intérprete final de la Convención" 18 . Por consiguiente esa convención gozaría de una primacía sobre los ordenamientos jurídicos nacionales y de esta suerte "la Convención Americana es la normatividad internacional de superior jerarquía a la que está subordinada el derecho interno (Constitución, leyes, actos administrativos, jurisprudencia, prácticas administrativas y judiciales, etc.) del Estado parte. Se trata de un vínculo jurídico de supra y subordinación del derecho nacional (derecho constitucional, derecho administrativo, etc.), respecto del Derecho Internacional de los Derechos Humanos, constituyendo así la Supremacía de la Convención Americana, entendiendo que el derecho interno es un derecho infraconvencional" ${ }^{\prime 19}$. Lo que no sería incompatible con el rol asignado a la Constitución Política como fuente

\footnotetext{
${ }^{14}$ Sagüés, N., "Obligaciones internacionales y control de convencionalidad”, en Estudios Constitucionales, Centro de Estudios Constitucionales de Chile, Talca, 2010, pp. 125 y 126.

15 De hecho, nos dice Kai Ambos, "la Corte, en resumidas cuentas, se ha convertido en una cuarta instancia (una 'Superrevisioansinstanz') que interpreta la Convención como una Constitución de los Estados Americanos ("control de convencionalidad") de la cual se derivan obligaciones con efecto directo y sobre todo muy concretas de los Estados miembros. Si bien la Corte acepta que está vinculada por la Convención, la interpreta, para decir lo menos, con mucha libertad, incluso al punto de exceder los parámetros de una interpretación admisible tal como está prevista en la convención de Viena sobre el derecho de los Tratados (...)". Ambos, K., "Protección de Derechos Humanos e Internacionalización del Derecho Penal", en Internacionalización del Derecho Constitucional, constitucionalización del Derecho Internacional, Editorial Eudeba, Buenos Aires, 2012, pp. 121.

${ }^{16}$ Gordillo, Agustín. Derechos Humanos. Buenos Aires: Fundación de Derecho Administrativo, 2005, pp. III-7, 8.

${ }^{17}$ Gordillo, A., Derechos Humanos, op. citada, pp. III-1.

${ }^{18}$ Rey, E. Control de convencionalidad de las leyes y derechos humanos. Editorial Porrua, México, 2008, pp. XLIX

19 Ídem.
} 
primera del ordenamiento jurídico, por cuanto es ella misma quien consiente remitirse a la normativa internacional y sujetarse a un orden normativo superior. Que por lo demás no lo reemplaza, sino que lo complementa vigorizando su fuerza normativa ${ }^{20}$.

Esta es, al menos, la interpretación que le dan algunos autores -los partidarios de esta forma de control supranacional- a la jurisdicción de la Corte. Esta jurisdicción, como es evidente, constituiría no solo fuente de derecho internacional, sino que tendría un carácter imperativo para todos los poderes de los Estados partes en la Convención Americana, rompiendo con la forma de entender el alcance restringido y auxiliar de las decisiones internacionales que examinamos en un principio. Esto no solo constituye una novedad en sí misma para el derecho internacional y para los ordenamientos jurídicos interamericanos, sino que podría comportar una restricción importante a los poderes locales en razón del amplio alcance que la Corte le ha dado a las cláusulas de la Convención Americana, que incidiría directamente en una reducción de la soberanía estatal $^{21}$.

\section{El EXAMEN DE CONVENCIONALIDAD. El RESPALDO CONSTITUCIONAL Y EL MARGEN DE APRECIACIÓN NACIONAL}

Como vimos con anterioridad, la tesis del control de convencionalidad ubica las sentencias y opiniones consultivas de la CIDH como fuente de derecho interna de los países que han suscrito la Convención Americana de Derechos Humanos. El control de convencionalidad comporta sostener que las decisiones de la $\mathrm{CIDH}$ tienen aplicación directa en los países sometidos a su jurisdicción y las sitúa además como parámetro de aquello que no es "susceptible de ser decidido" por parte de las mayorías ${ }^{22}$.

Lo que intentaremos ahora es reflexionar en torno a esto último. Identificaremos los puntos de tensión de esta doctrina y sugeriremos algunas ideas que pueden ayudar a ponderar y eventualmente resolver el conflicto que puede generar el alcance de las decisiones de la CIDH versus las decisiones democráticas adoptadas por los pueblos en virtud de su derecho a la autodeterminación (consagrado en el primer artículo de ambos pactos internacionales de derechos humanos).

${ }^{20}$ Bidart, G., El derecho de la Constitución y su fuerza normativa, México, IIJ- UNAM, 2003, pp. 261, 266 y 267.

${ }^{21}$ Para un autor, por lo demás muy crítico del rol que ha venido cumpliendo el tribunal interamericano en este aspecto, la CIDH mediante sus fallos ha ido "reescribiendo la Convención Americana tanto en aspectos relacionados con los derechos de la persona como en asuntos referidos a la competencia y la función del tribunal", ampliando de este modo con sus decisiones "en gran medida, por un lado, su poder de control (ampliación de la base jurídica y temporal -y con ello fáctica- sobre la cual puede pronunciarse) y, por el otro, su poder de imposición (ampliación de lo que puede ordenar como reparación y de los casos en que puede hacerlo)". Cfr. Cfr. Malarino, E., "Activismo judicial, punitivización y nacionalización. Tendencias antidemocráticas y antiliberales de la Corte Interamericana de Derechos Humanos", en Sistema Interamericano de Protección de los Derechos Humanos y Derecho Penal Internacional, Tomo II, Konrad Adenauer Stifung, 2011, pp. 32 y 33.

${ }^{22}$ CIDH, Caso Gelman vs. Uruguay, párr. 239. 
Como ha señalado Armin von Bogdandy, las normas y decisiones internacionales a las que se le atribuye claramente efecto directo son muy escasas. Las grandes excepciones a esta regla son, por un lado, el derecho de la Unión Europea, y, en segundo lugar, "la jurisprudencia de la Corte Interamericana de Derechos Humanos, que atribuye efecto directo a sus pronunciamientos". Y agrega el autor que de tener éxito la doctrina del control de convencionalidad por la Corte Interamericana, esta "pasará de ser una institución internacional a una institución supranacional" 23 .

¿Qué podría justificar este alcance a las decisiones de la CIDH? ¿Cuáles son las condiciones de posibilidad que la harían plenamente posible su aplicación?

Siendo así, es decir, si el control de convencionalidad tiene las implicancias que señala Von Bogdandy, se requeriría para su consolidación de dos condiciones de posibilidad que hasta ahora no parecen plenamente satisfechas: primero, la explícita autorización constitucional, desde el punto de vista interno, y, segundo, la incorporación de la doctrina del margen de apreciación nacional, desde el punto de vista internacional. Veamos ahora estas dos cuestiones.

\subsection{El respaldo constitucional}

Respecto del primer punto, la decisión de un tribunal supranacional a favor del efecto directo de sus decisiones en los países que están bajo su jurisdicción solo podrían estar plenamente legitimadas si están respaldadas por normas constitucionales ${ }^{24}$. La verdad, no es posible hacer exigible una norma externa, sin que alguna disposición de carácter constitucional autorice su aplicación en el país, "en tanto norma suprema que regula la actividad normativa de las autoridades nacionales y permite, según sus términos, la apertura del sistema jurídico interno a las disposiciones provenientes de terceros ordenamientos" 25 . Ello porque "más allá de la clásica discusión entre las doctrinas dualista y monista, las relaciones que tienen lugar entre el ordenamiento interno y el de origen internacional, en los hechos, se mantienen en dos esferas distintas de actuación; siendo el Estado en el ámbito nacional el soberano que en tanto tal acepta vincularse en lo externo con sus demás pares, teniendo ello incidencia en la fase interna, en la medida establecida y voluntariamente consentida por las propias autoridades". Por lo mismo, siempre se requerirá en definitiva "una actuación estatal que habilite la incidencia del derecho internacional en el interior del Estado" 26.

${ }^{23}$ Von Bogdandy, A., "Del paradigma de la soberanía al paradigma del pluralismo normativo. Una nueva perspectiva (mirada) de la relación entre el derecho internacional y los ordenamientos jurídicos nacionales", en Griselda Capaldo, Jan Sieckmann y Laura Clérico (Directores), Internacionalización del Derecho Constitucional, op. cit., pp. 28 y 29.

${ }^{24}$ Ibid., pp. 29.

25 Perotti, A., Habilitación constitucional para la integración comunitaria, Estudio sobre los Estados del Mercosur, Tomo I: Brasil y Paraguay, Montevideo 2004, Universidad Austral, pp. 31 y 32.

${ }^{26}$ Ibid., pp. 33. 
De este modo, la Constitución junto con fundar la existencia de las normas creadas internamente (normas de generación interna), según la tramitación respectiva que dispone el propio ordenamiento jurídico (que de otro modo no podrían nacer a la vida del derecho), también se remite y hace aplicable a nivel interno normas que tienen su origen en el ámbito internacional, de acuerdo con las formas de creación propias de ese otro sistema jurídico (normas de generación externa). Ambos tipos de normas, las generadas internamente y las generadas externamente, de conformidad con lo dispuesto por la propia Constitución -emanada del poder constituyente- pasan a formar parte del orden jurídico vigente, siendo ambas, en todo caso, igualmente aplicables ${ }^{27}$.

Con todo, se puede dar más de una fórmula constitucional para permitir la apertura a las normas externas. Así, pueden existir cláusulas constitucionales que regulen lo relativo a las relaciones internacionales y a los tratados con los demás sujetos del derecho internacional, una fórmula que podríamos llamar clásica. En un sentido diverso, pueden existir cláusulas de incorporación del derecho de los tratados de derechos humanos al orden jurídico nacional, como ha sucedido con el caso de varios países latinoamericanos bajo distintas modalidades ${ }^{28}$. Y por último, pueden existir cláusulas de habilitación o atribución de competencias a órganos externos para instituir marcos de integración ${ }^{29}$, generalmente de carácter económico como es el caso del Mercosur ${ }^{30}$. Esta diferenciación traduce distintas formas de abordar la incorporación del derecho de origen exterior, y señala respuestas diversas en el orden interno.

${ }^{27}$ De esta suerte, es el mismo poder soberano el que crea, en conformidad con las reglas que se ha impuesto, la normativa interna, y el que hace aplicable internamente las normas procedentes del Derecho Internacional, remitiéndose a ellas. Todo ello según a la Norma Fundamental. Requejo Pages lo expresa así: "Del mismo modo que el derecho interno no condiciona la validez de las normas del derecho internacional, así tampoco estas inciden en la validez de aquellas, razón por la que, entre ordenamientos cuyos criterios de existencia jurídica en nada se confunden, no queda otro remedio que acudir a la idea de aplicación como pauta integradora de sus normas respectivas". Ver, Requejo, J., "Consideraciones en torno de las normas internacionales en el ordenamiento español", en Revista Española de Derecho Constitucional, Centro de Estudios Constitucionales, España, 1992, volumen 44, enero-abril, pp. 61.

28 Ver, Manili, P. "La recepción del derecho internacional de los derechos humanos por el derecho constitucional iberoamericano”, en Internacionalización del Derecho Constitucional..., op. cit, pp. 473 a 506.

${ }^{29}$ En Chile, el constitucionalista Francisco Zúñiga rechaza la doctrina del margen de convencionalidad, entre otras razones, porque "la Constitución estatal contiene una regla de incorporación del derecho de los tratados y no una regla de habilitación”. Asimismo, la competencia propia de la CIDH, a su juicio, corresponde a una "jurisdicción complementaria, subsidiaria, integrante de un sistema de protección internacional-regional de derechos humanos y no de un sistema supranacional de protección”. Zuñiga, F., "Control de Convencionalidad y tribunales nacionales. Una aproximación crítica”, en Nogueira H. (coord.), El diálogo transjudicial de los Tribunales Constitucionales entre sí y con las Cortes Internacionales de Derechos Humanos, Librotecnia, 2012, pp. 433 y 435.

30 Perotti, en relación con la integración económica, nos habla de cláusulas constitucionales que permiten la participación de los países en acuerdos de integración de tipo intergubernamental y cláusulas que autorizan acuerdos de tipo supranacional, entendiendo estos últimos aquellos que "contienen órganos desvinculados de las autoridades nacionales, conformados por miembros que actúan con plena autonomía e independencia, a los que les sea transferido el ejercicio de ciertas competencias para ser administradas en beneficio de la comunidad regional y en base a las cuales puedan dictar normas obligatorias". Perotti, A., Habilitación constitucional..., op. cit., pp. 36 y 37. 
En el caso de la Convención Americana, y los países que han aceptado la jurisdicción de la CIDH, existen buenas razones para aceptar que una cláusula de incorporación de su derecho (como es el caso de Chile por el artículo $5^{\circ}$ inciso $2^{\circ}$ de su Constitución Política) es suficiente para justificar el control de convencionalidad. Ello por las siguientes razones.

En primer lugar, por la coincidencia de los órdenes jurídicos nacionales y el internacional. A la cúspide de los ordenamientos jurídicos nacionales, que representan sus constituciones, se superpone, potenciándose, la cúspide del derecho interamericano, teniendo ambos a los derechos humanos en su vértice ${ }^{31}$. Ambos reconocen en la persona humana y en su dignidad su máximo sustento y objetivo ${ }^{32}$. La opción constitucional por el respeto y promoción de los derechos humanos entregan una base jurídica para entender que existe un imperativo jurídico en el cumplimiento de los más altos estándares internacionales fijados por ese mismo organismo especializado e intérprete último de la Convención Americana.

En segundo lugar, como se sugirió con anterioridad, una vez integradas las normas internacionales al sistema nacional, es nuevamente el Derecho Internacional el que determina la manera en que deben ser aplicadas, según sus propias normas de observancia, de interpretación y también según el sentido que le hayan dado los órganos de control o judiciales encargados de aplicar los tratados de derecho internacional como es el caso de la jurisprudencia de la CIDH. "El tratado no es generado por una fuente de derecho interna, sino por fuente internacional, por tanto su validez y vigencia se rigen por normas de derecho internacional", ha afirmado al respecto Humberto Nogueira ${ }^{33}$. El origen de la norma internacional determina las condiciones de aplicabilidad de las normas de origen internacional, integradas al sistema nacional, por cuanto ellas mismas disponen por sí mismo "la forma en que deben ser aplicadas una vez que los Derechos nacionales las han convertido en aplicables" 34 . Y por lo mismo una doctrina como la del control de convencionalidad puede encontrar un apoyo lógico en lo que aquí se expresa.

Asimismo, incluso más allá de la remisión constitucional, en los países que hayan reconocido la jurisdicción de la Corte Interamericana se justifica su vinculación jurídica con las decisiones interamericanas por tres razones: 1) por el principio de buena fe que

31 Ver, Gordillo, A., en Derechos Humanos, Fundación de Derechos Administrativos, Buenos Aires, 2005 , pp. 75 y 76.

${ }^{32}$ En el plano universal, para Bidart Campos, en relación con la Constitución argentina, "así como los derechos oriundos de la Constitución encabezan con ella el derecho interno del Estado, por el artículo 103 de la mencionada Carta [de las Naciones Unidas] también se sitúan en la cúspide del derecho internacional, con lo que se opera una ventajosa simetría: la pirámide del derecho interno y la pirámide del derecho internacional elevan los derechos humanos a la cima de sus respectivos vértices". Bidart, G. "El panorama de los derechos humanos a fin de siglo" [en línea]. Biblioteca Jurídica Virtual. UNAM. Disponible en la web: http://www.bibliojuridica.org/libros/1/114/5.pdf

${ }^{33}$ Nogueira, H., "Aspectos fundamentales de la reforma constitucional de 2005 en materia de tratados internacionales”, en La Constitución Reformada de 2005, Centro de Estudios Constitucionales de Chile, Santiago, 2005, pp. 47.

${ }^{34}$ Requejo, J., "Consideraciones en torno de las normas internacionales en el ordenamiento español”, Revista Española de Derecho Constitucional, Centro de Estudios Constitucionales, España, 1992, volumen 44, enero-abril, 1992, pp. 51. 
debe regir el cumplimiento de las obligaciones internacionales, principio que implica reconocer autoridad a las decisiones de los órganos de supervigilancia dispuestos en los mismos instrumentos suscritos por los Estados; 2) por la obligación que genera la doctrina del acto propio o también llamado estoppel a partir del momento que el Estado parte declaró "que reconoce como obligatoria de pleno derecho y sin convención especial, la competencia de la Corte sobre todos los casos relativos a la interpretación o aplicación de esta Convención" (artículo 62, inciso $1^{\circ}$ del CADH); y 3) por el deber de las autoridades nacionales de evitar hacer incurrir al Estado en responsabilidad internacional por incumplimiento de sus obligaciones internacionales, entendiendo que el examen de convencionalidad que exige actualmente la Corte Interamericana es la consecuencia de un sistema de protección de los derechos humanos ${ }^{35}$.

De este modo, el hecho de que las constituciones incorporen los tratados internacionales de derechos, si bien no constituyen normas estrictas de habilitación supranacional, sí permiten reconocer la autoridad de la Corte para interpretar las normas de la Convención Americana de una manera amplia y extendida (en función de su artículo 29 que entrega un amplísimo margen a dicha interpretación).

Con todo, el respaldo constitucional para la doctrina del control de convencionalidad es una construcción teórica susceptible de controversia. Para que un sistema como el que pretende consagrar la Corte tenga finalmente éxito, sería conveniente avanzar en una explícita consagración constitucional que reconociera fuerza autoritativa a las interpretaciones dadas por dicho tribunal a las cláusulas del tratado. De otro modo su fuerza legal puede quedar sujeta a las distintas interpretaciones locales.

Eso es la parte que le toca a los Estados miembros, ahora veamos la parte que le toca a la Corte.

\subsection{El margen de apreciación nacional}

No obstante que es posible sustentar constitucionalmente, como se vio con antelación, la doctrina del examen de convencionalidad, esa doctrina tal cual está expresada hoy le faltaría adoptar una perspectiva más realista. Tal y como está presentada -sin incluir un margen de apreciación nacional en los casos en que esto es aceptable-constituye una respuesta demasiado lógica y jurídica que olvida, por lo mismo, las condiciones fácticas en que se desenvuelve el derecho internacional. El derecho internacional es un sistema autorregulado, y su existencia y alcance depende en último término de los Estados. Parece a ratos que la $\mathrm{CIDH}$ ha inadvertido estas circunstancias y cae, parafraseando a Sagüés,

35. Como lo pusiera de relieve en una oportunidad el juez de la Corte Suprema argentina Antonio Boggiano, "de nada serviría la referencia a los tratados hecha por la Constitución si su aplicación se viera frustrada o modificada por interpretaciones basadas en uno u otro derecho nacional". "Precisamente -agregael fin universal de aquellos tratados solo puede resguardarse por su interpretación conforme al derecho internacional, lo contrario sería someter el tratado a un fraccionamiento hermenéutico por las jurisprudencias nacionales incompatible con su fin propio" (voto del ministro de la Corte Suprema argentina, doctor Antonio Boggiano, en la causa Arancibia Clavel, Enrique Lautaro s/ homicidio calificado y asociación ilícita y otros, de 24 de agosto de 2004). (Nota del Autor) 
en una suerte de "autismo jurídico" que la ha llevado en ocasiones a interpretar los derechos humanos exclusivamente desde los estándares internacionales "desconociendo las realidades y el contexto normativo del Estado donde se debate una posible infracción a aquellos derechos" ${ }^{36}$ y, también, comprometiendo el derecho de autodeterminación de los pueblos, que si bien no autoriza a desconocer los derechos individuales por parte de la comunidad, entrega un espacio para precisar sus contenidos y alcances ${ }^{37}$.

Los defensores acérrimos de la doctrina del examen de convencionalidad probablemente desatienden dos preguntas claves: 1) ¿cuáles son las normas jurídicas internacionales?, y 2) ¿sobre qué base se funda su obligatoriedad? La respuesta del control estricto de convencionalidad desestimaría el rol que en el derecho internacional siguen cumpliendo los Estados y, más aún en relación con la vigencia del derecho de origen externo en sus propios territorios. El elemento decisivo para identificar las normas que obligan a los Estados sigue pasando por el consentimiento de ellos: son sus creadores y principales destinatarios. Asimismo, el fundamento de su obligatoriedad descansa en la convicción por parte de esos mismos Estados de que esas normas son convenientes, incluso necesarias, y su cumplimiento responde a la "adecuación recíproca de sus intereses particulares y a la defensa y protección de sus intereses comunes" 38 .

Es cierto que los intereses entre el sistema interamericano y los países que lo conforman hasta ahora más o menos han confluido. Gran parte de los gobiernos latinoamericanos que recuperaron la democracia "comenzaron con una política proactiva de derechos humanos y consideraron a la Corte como aliada contra las viejas estructuras" 39 . Ambos persiguieron la misma política de promoción de los derechos humanos. Pero eso no necesariamente va a seguir siendo así (ya hay signos que no es así), y por lo mismo hay que buscar un mecanismo que más que asentarse sobre la imposición de uno sobre

\footnotetext{
${ }^{36}$ Sagüés, N., "Las relaciones entre los tribunales internacionales y los tribunales nacionales en materia de derechos humanos. Experiencias en Latinoamérica”, en Revista Ius et Praxis, vol. 9, n. 1, Talca, 2003. En ese mismo texto el autor advierte acerca del peligro por parte de los tribunales internacionales de adoptar actitudes "hedonistas y narcisistas de pésimos resultados, como creer que por tratarse de un ente jurisdiccional supremo, cuyos veredictos son irrecurribles, es posible resolver ligera, mayestática y soberanamente los casos, sin medir con responsabilidad y tino las consecuencias previsibles del pronunciamiento, la factibilidad de su ejecución, o el impacto probable en situaciones futuras dentro y fuera del país involucrado por la sentencia".

37 Según Ximena Fuentes, "la doctrina de margen de apreciación tiene un fundamento de mucho más peso, que se concentra en el problema de equilibrar en su justa medida las facultades de supervisión que se entregan a ciertos órganos supranacionales con el poder soberano de los pueblos para determinar sus propias leyes. En este sentido, la doctrina del margen de apreciación guarda estrecha relación con los debates que se han dado a nivel nacional sobre el ámbito adecuado de la revisión judicial o constitucional de la legislación. De esta manera, no se trata simplemente de una deferencia hacia la identidad cultural de cada país, sino que a través de la doctrina del margen de apreciación se ha tratado de preservar el valor de la democracia". Fuentes, X., "La protección de la libertad de expresión en el sistema interamericano de derechos humanos y la promoción de la democracia”, en Revista de Derecho, Vol. XIII, Santiago, diciembre 2002, p. 242.

${ }^{38}$ Mariño, F. en Derecho Internacional ..., op. cit. pp. 62, 213 y 214. El principio del consentimiento estatal, junto con el de la subjetividad originaria de cualquier ente estatal y el principio de autoprotección de cada Estado de sus intereses, son los tres principios que conforman la organización del orden internacional según el autor español.

39 Ambos, K., "Protección de Derechos Humanos e Internacionalización del Derecho Penal". En Internacionalización del Derecho Constitucional..., op. cit. p. 123.
} 
otro, permita un diálogo fructífero entre el derecho local y el internacional. Más todavía cuando existe el peligro de que una de las partes se quede hablando sola.

En ese sentido, son muy oportunas las palabras de la jueza del Tribunal Federal Alemán Gertrude Lübble-Wolff cuando aboga por no intentar cerrar el sistema que forma el sistema local e internacional de protección de los derechos humanos. Nos dice, desde su experiencia como magistrada, que "el mundo real no pude ser redimido de sus conflictos reales con meras construcciones teórico-jurídicas y existen razones para preguntarse si a largo plazo no podría resultar más útil al derecho y a la paz soportar una tensión entre el derecho nacional y el derecho internacional, que postular un sometimiento incondicional, y en consecuencia también ilimitado, a uno de esos regímenes jurídicos, el internacional, a partir del cual las partes contratantes de tratados internacionales y los Estados miembros de organizaciones supranacionales, renuncian a toda posibilidad de tener voz y voto a la hora de decidir cuáles son los límites de su inserción en contextos supranacionales y en tratados de derecho internacional".

Y agrega la misma magistrada, " $[1]$ os derechos humanos podrán reivindicar una vigencia universal, a partir de la cual los tribunales internacionales de derechos humanos deduzcan una dignidad especial. Sin embargo, esto en nada modifica el hecho que el contenido esencial de muchos derechos sectorialmente no es más que un postulado de ponderación, y que en esta ponderación debida pueden incidir factores muy diversos de país en país. Eso en nada modifica que la vigencia fáctica y la realizabilidad de los estándares en derechos humanos depende de evoluciones materiales e intelectuales y que estos estándares no pueden garantizarse de manera equivalente a cualquier nivel. Tampoco cambia en nada el hecho de que los sistemas internacionales de defensa de los derechos humanos hermanos deben respetar un cierto grado de diferencias nacionales, que por lo tanto no están concebidos como sistemas para la unificación de estándares de derechos individuales, sino como sistemas diseñados para preservar un estándar mínimo que debe respetar ciertos márgenes de apreciación nacionales, en particular el alcance de las limitaciones admisibles. Y en nada modifica el hecho que también una jurisdicción de los derechos humanos puede exceder los límites de sus facultades" ${ }^{40}$.

A este respeto se suman otras consideraciones. No existe, como dice Eduardo Sodero, "algo así como un dogma de infalibilidad del tribunal internacional", y la falta de control sobre la acción de sus miembros nos enfrenta a un cuestionamiento serio de déficit democrático ${ }^{41}$. En ese contexto, una interacción jurisdiccional, en varios niveles y de jerarquías entrelazadas ${ }^{42}$, en materias que pueden ser debatibles, constituye probablemente un mecanismo mucho más fecundo, y permite evitar caer en los "autismos"

${ }^{40}$ Lübble-Wolff, G., "Justicia constitucional y justicia internacional: cooperaciones, conflictos y tensiones”, en Internacionalización del Derecho Constitucional ..., op. cit. pp. 102 y 103.

${ }^{41}$ Sodero, E., "Precedente e internacionalización del derecho constitucional", en Internacionalización del Derecho Constitucional ..., op. cit. p. 470.

42 Sobre el término "jerarquías entrelazadas" en un "sistema jurídico mundial de niveles múltiples" ver, Neves, M., "Transcontitucionalismo, con especial referencia a la experiencia latinoamericana", en Internacionalización del Derecho Constitucional ..., op. cit. p. 55. 
judiciales de que nos habla Néstor Sagüés ${ }^{43}$. De lo que se trataría, en consecuencia, es de adoptar un modelo funcional que tenga en cuenta, por un lado, la "fragmentación" (falta de unidad) en la sociedad mundial y, por otro lado, la "utopía constitucional" de la comunidad internacional.

Este modelo, transconstitucionalista, antes que la instalación de una autoridad última, postularía la articulación de un método que permita administrar la "trama" de los fragmentos. Como dice Neves, se trata de que "diversos órdenes jurídicos entrelazados en la solución de un problema -caso constitucional, a saber, de derechos fundamentales o humanos y de organización legítima del poder-, que les sea concomitantemente relevante, deben buscar formas transversales de articulación para la solución del problema, cada uno de ellos observando a otro, para comprender sus propios límites y posibilidades de contribuir para solucionarlos. Su identidad es reconstruida, de esta manera, mientras toma en serio la alteridad, la observancia del otro (...)" ${ }^{44}$.

En esta perspectiva se deben tomar en cuenta dos realidades cruzadas que se articularían en una dialéctica que no deja de ser compleja:

1. La primera dice relación con reconocer la función que siguen cumpliendo los Estados para la vigencia de los derechos humanos. Sin duda que hay muy buenos motivos para tener una considerable sospecha de ellos en ese papel, porque han sido los actores que han estado involucrados directamente con las violaciones, a veces masivas y sistemáticas, de esos mismos derechos. Pero, a su vez, no hay que olvidar que en la práctica, "debido a la falta de capacidad de la comunidad internacional, el Estado soberano debe continuar siendo el actor fundamental en cualquier estrategia que se diseñe para asegurar la promoción y el respeto de los derechos humanos". Asimismo, el Estado sigue desempeñando en última instancia un rol legitimador del derecho internacional al expresar el consentimiento acerca de dicha normativa (amén de su función de contención y compensación de las consecuencias negativas que puede generar la globalización $)^{45}$.

2. Junto a lo anterior, hay que tomar nota de la cruda realidad latinoamericana en relación con la vigencia de los derechos humanos. Cançado Trindade rechaza la doctrina del margen de apreciación en el ámbito americano precisamente porque

43 Para el argentino Néstor Sagués la doctrina del margen de apreciación nacional podría servir como antídoto frente a la posibilidad de que los tribunales internacionales pueden practicar una suerte de "autismo jurídico que los lleve a interpretar los derechos humanos emergentes de un instrumento internacional solamente 'desde' tal documento, desconociendo las realidades y el contexto normativo del Estado donde se debate una posible infracción a aquellos derechos". Sagués, N., "Las relaciones entre los tribunales internacionales y los tribunales nacionales en materia de derechos humanos: experiencias en Latinoamérica”, en Revista Ius et Praxis, Talca, 2003, vol.9, n.1.

${ }^{44}$ Neves, M., "Transcontitucionalismo, con especial referencia a la experiencia latinoamericana", en Internacionalización del Derecho Constitucional ..., op. cit. p. 67.

45 Barreiros, L., "El derecho internacional contemporáneo y el problema de la soberanía. Un intento de reconciliación”, en Pinto M. (compiladora), Las fuentes del derecho internacional en la era de la globalización, Editorial Eudeba, Buenos Aires, 2009, p. 83. 
ella "presupone la existencia de Estados verdaderamente democráticos, con un Poder Judicial indudablemente autónomo" ${ }^{46}$. Para el magistrado brasileño la inexistencia de este requisito en Latinoamérica haría de la aplicación de esta doctrina algo insensato: "[c]ómo pretender aplicarlo [el margen de apreciación] en un sistema regional en el que el Poder Judicial de tantos países sufre todo tipo de presiones e intimidaciones. Cómo pretender aplicarlo en un continente en que la función judicial en tantos países sigue siendo 'compartida' por el fuero ordinario o común, y fueros militares especiales. Cómo pretender aplicarlo en relación con ordenamientos jurídicos nacionales severamente cuestionados por su ineficacia en el combate a la impunidad. En nuestro sufrido continente -así como en la panEuropa convulsionada de hoy- difícilmente encontraríamos la premisa básica sobre la que se ha erigido en las últimas décadas la doctrina del 'margen de apreciación' de los Estados en cuanto a los modos de cumplimiento de sus obligaciones convencionales en materia de derechos humanos. Siendo así, no resta otro camino sino el fortalecimiento de los mecanismos internacionales de protección, complementarios de las instancias internacionales" ${ }^{77}$. Esta situación de grave déficit institucional y democrático haría por tanto del todo imprudente mostrar mucha deferencia al país de que se trata, y autorizaría aplicar sin ninguna contemplación los estándares de derechos humanos según el jurista brasilero.

Este es el inevitable escenario en que nos movemos y que hay que intentar conciliar: estamos frente a un derecho internacional de los derechos humanos, que por un lado requiere de la colaboración activa de los Estados, por lo que no es posible avanzar en estrategias judiciales o de otra naturaleza que se implemente a pesar de los Estados; pero por otro lado estamos frente a realidades dramáticas, al menos en algunos países americanos, de debilidad institucional y de graves y sistemáticas violaciones a los derechos humanos. Ello exige una respuesta diferenciada en relación con el escrutinio de los tribunales internacionales sobre las decisiones locales. Y para ello resulta útil tener en cuenta los postulados de aquellos autores que enfrentan disyuntivas similares y que abogan por un "constitucionalismo débil" en relación con la revisión constitucional de las leyes ${ }^{48}$.

Esta respuesta diferenciada va a depender del grado de desarrollo democrático del país en cuestión. Aquellos Estados que gozan de niveles aceptables de institucionalidad democrática, tienen que seguir percibiendo que una justicia internacional de los derechos humanos responde de alguna forma con sus intereses, precepción que se pone en riesgo si la Corte adopta decisiones irrevocables sobre cuestiones complejas, en donde

\footnotetext{
${ }^{46}$ Cançado, T., El Derecho Internacional de los Derechos Humanos en el siglo XXI, Editorial Jurídica de Chile, Santiago, 2006, p. 388.

47 Ibid., p. 390.

48 Ver, Bayón, J., "Democracia y derechos: problemas de fundamentación del constitucionalismo", en Carbonell M. y García, L. (editores), El canon neoconstitucional, Editorial Trotta, 2010, pp. 285 a 355.
} 
aparece que la decisión mayoritaria pueda estar más legitimada y en mejores condiciones epistemológicas para adoptar una decisión.

Y esto es de vital importancia bajo el entendido que el control de convencionalidad postulado por la CIDH puede transformar en "cotos vedados" muchos temas susceptibles de amplios debates democráticos. Un uso excesivo del control de convencionalidad podría dar lugar a lo que Juan Carlos Bayón identifica como "la paradoja de las precondiciones de la democracia" ${ }^{49}$, es decir, un sistema jurídico que hasta tal punto se vuelve respetuoso de los derechos de las personas (definidos en términos amplios por una autoridad ajena a la mayoría o por constituciones rígidas), que disminuye hasta lo insustancial el margen de decisión política por parte de los ciudadanos.

Al respecto es saludable recordar que, como nos recuerda Jeremy Waldron, entre nosotros existen genuinos desacuerdos. Discrepamos respecto de cuestiones relativas a la verdad pero también acerca de lo relativo a la justicia, y las diferencias alcanzan también a materias de derechos: ¿Qué derechos deben ser reconocidos a las personas? ¿Cuáles son sus alcances y los contenidos de los mismos? Nuestras diferencias son de buena fe, no necesariamente impulsados por autointerés o por alguna deficiencia cognitiva. Y por lo mismo, parece problemático que en estas materias sean los tribunales los llamados a dar cuenta de la última palabra ${ }^{50}$.

Esta disyuntiva, relativa a la que ampliamente ha debatido la teoría política entre los constitucionalistas o neoconstitucionalistas y quienes rechazan la posibilidad de revisión judicial de las leyes, es conocida y no hay espacio para desarrollarlo acá ${ }^{51}$. Solo diremos que nuestra postura en esta controversia es la defendida por Juan Carlos Bayón, quien aboga por un "constitucionalismo débil" que incorpora en la solución el valor intrínseco de la regla de la mayoría y el valor instrumental que representa el control judicial de las leyes para la vigencia de los derechos ${ }^{52}$. El balance exacto entre uno y otro

49 Bayón, J., "Democracia y derechos: problemas de fundamentación del constitucionalismo”, en Carbonell M. y García L. (editores), El canon neoconstitucional, Editorial Trotta, 2010, p. 298.

${ }^{50}$ De acuerdo con la filosofía defendida por Waldron, la política está signada por dos condiciones ineludibles: la existencia de desacuerdos y la necesidad percibida por todos de un curso de acción común. Ello nos obliga a definir un procedimiento que nos permita decidir cuál es la alternativa que vamos a adoptar, una instancia con autoridad que nos permita tomar decisiones legítimamente. Ese procedimiento naturalmente no debe de antemano inclinarse por una u otra respuesta, acerca de cuál es la respuesta correcta (justo o injusto), de hecho la autoridad la designamos precisamente para resolver estas cuestiones sobre las cuales no tenemos acuerdo. Pero sí debe ser un mecanismo que honre de mejor manera los valores de igualdad y autonomía, que son los mismos que inspiran los derechos humanos. Y ese procedimiento es el democrático mayoritario por cuanto honra de mejor modo esos valores, y la autoridad para decidir políticamente se va a adjudicar a un Parlamento que represente las distintas opciones de los ciudadanos y que permita un juego de perspectivas lo más amplia posible para tomar las decisiones públicas. Waldron, J., Derecho y Desacuerdo, Maricial Pons, Madrid-Barcelona, 2005.

${ }^{51}$ Los términos del debate están expuestos con bastante detalle en Linares, Sebastián, La (i)legitimidad democrática del control judicial de la leyes, Marcial Pons, Madrid-Barcelona-Buenos Aires, 2008.

52 Para una revisión de los distintos sistemas de control judicial de las leyes, incluyendo aquellos que dejan la última palabra institucional al Parlamento, ver, Linares, Sebastián, La (i)legitimidad democrática ..., Op. cit., pp. 200 a 219. 
va a depender del contexto institucional y social de cada país, y en ese sentido pueden existir muy buenas razones para inclinar la balanza a favor de un rol más activo por parte de la justicia internacional, en aquellos países donde existen grandes asimetrías estructurales y que dejan a algunas minorías sistemáticamente menoscabadas en sus derechos por las decisiones mayoritarias ${ }^{53}$. Ello justifica una intervención decidida de los tribunales internacionales por cuanto ellos gozan de mayor independencia e imparcialidad respecto de las condiciones internas de los países. Y están por ello mejor situados para servir de correctivo frente a sociedades que adolecen de graves déficit de democracia o de representación ${ }^{54}$. De hecho, la contribución del sistema interamericano de derechos humanos a la vigencia de estos es una cuestión que hay que destacar. Específicamente la judicialización de los derechos humanos a nivel internacional, ha permitido importantes progresos para la profundización democrática en muchos países latinoamericanos ${ }^{55}$.

Pero esa no puede ser la única respuesta. Es necesario establecer una diferenciación por parte de la CIDH dependiendo del contexto institucional y de la naturaleza de las violaciones a los derechos humanos que se están conociendo. Como dice el profesor Manuel Núñez, uno de los autores latinoamericanos que más ha abogado por la necesidad de reconocer un "margen de apreciación nacional", cuando se juzga la responsabilidad internacional de los países, "[t]ratándose, por ejemplo, de la prohibición de la tortura, de las desapariciones forzadas (práctica que desgraciadamente fue corriente en décadas pasadas), de las detenciones y ejecuciones ilegales, no cabe duda que la doctrina del margen de apreciación no puede tener aplicación”, lo que no deja de ser "importante si se tiene en consideración que cerca de dos tercios de las denuncias en el sistema interamericano se refieren a la vida e integridad de las personas" 56.

El margen de apreciación nacional no podría tener lugar, o solo de una manera muy reducida, en relación con aquellas cuestiones que refieran a discriminaciones, tan usuales en nuestro continente -no pudiendo perder el sistema interamericano su encomiable labor de promoción del cambio social en esta materia ${ }^{57}$, ya sea tratándose de personas

53 Como lo explica Bayón: "aunque el conflicto entre el valor intrínseco y el valor instrumental de un procedimiento es siempre posible, las circunstancias sociales en las que el procedimiento mayoritario realiza en mayor medida su valor intrínseco tienden a coincidir con aquellas en las que menos reticencias hay que tener en relación con su valor instrumental, con aquellas, en suma, en que son más escasas las razones para presuponer que, en comparación con él, desplegará sistemáticamente un mayor valor instrumental un procedimiento que incorpore restricciones contramayoritarias”. Bayón, J., El canon neoconstitucional, op. cit, p. 354.

${ }^{54}$ Por ejemplo, para el caso de Perú, ver Bazán, I., El Impacto de la Jurisprudencia de la Corte Interamericana de Derechos Humanos en el Perú. Una Evaluación Preliminar, en Revista Ars Boni et Aequi, Universidad Bernardo O’Higgins, vol. 7 Núm. 2, agosto 2011, pp. 283 a 317. Para el caso de Colombia, Acosta P., "Los casos colombianos ante el sistema interamericano y el uso del margen de apreciación ¿ausencia justificada?, en Acosta, P, Núñez, M. (coord.), El Margen de Apreciación en el Sistema Interamericano de Derechos Humanos: Proyecciones Regionales y Nacionales, Instituto de Investigaciones Jurídicas de la UNAM, México, 2012, pp. 183 a 238.

55 Ver, Nash, C., Relación entre el Sistema Constitucional e Internacional en Materia de Derechos Humanos, Centro de Derechos Humanos, Universidad de Chile, 2012.

${ }^{56}$ Cfr. Núnez, Poblete, "Sobre la doctrina del margen de apreciación nacional...", op. cit. p. 34.

${ }^{57}$ En relación con la discriminación contra las mujeres, ver Mann, L. [en línea], El Tribunal Europeo y la Comisión Interamericana de Derechos Humanos: diferencias de metodología y sus implicaciones. Disponible en la web: http://www.womenslinkworldwide.org/pdf_pubs/es_pub_cuerpos3.pdf 
o grupos desfavorecidos (verbigracia, en el caso de pueblos indígenas) ${ }^{58}$. Los tribunales internacionales pueden y deben servir de instrumentos "correctivos" de situaciones inaceptables de desigualdad. No hay que olvidar que la prohibición de no discriminación ha sido reconocida como una norma de jus $\operatorname{cogens}^{59}$ y por tanto imperativa para toda la comunidad internacional.

Pero otra debe ser la respuesta tratándose de "casos difíciles", es decir, situaciones en "que puede admitir más de una respuesta razonablemente justa y no, como ha quedado dicho, aquel tipo de problemas -usualmente tragedias- donde la respuesta es, o por lo menos debe ser, unívoca" 60 . En esos casos difíciles, sí resulta procedente reconocer un margen de ponderación local. Ello en atención a un mayor respeto a las realidades locales y al autogobierno democrático, compatibilizando un sistema de protección internacional con "las legítimas aspiraciones de diversidad por parte de aquellas comunidades que han logrado dejar atrás el fantasma de la dictadura" ${ }^{61}$. Ello vendría a traducir el principio general de subsidiariedad que debe regir las relaciones entre los sistemas de protección internacional y la justicia nacional, principio que según el profesor Núñez es el que "mejor permite manejar las tensiones propias de la dialéctica entre lo universal y lo particular" 62 .

Respecto de esta base, y recogiendo los mismos principios que recomiendan un "constitucionalismo débil", es posible sostener que en países que exhiben un desarrollo institucional democrático importante, y respecto de aquellos “casos difíciles", donde cabe más de una respuesta razonable, es legítimo, e incluso necesario, la deferencia que enseña la doctrina del margen de apreciación nacional. Por lo mismo, el alcance del examen de convencionalidad que propugna la Corte debiera incorporar una diferenciación clara a este respecto y evitar plantear como estándares universales criterios solo aplicables a realidades específicas.

Por último, ya para terminar, lo dicho no implica precisamente que en los "casos difíciles" la Corte deba renunciar a los estándares que ella u otros organismos han ido fijando en materia de derechos humanos. Junto con mostrar sensibilidad a las condiciones

58 Al respecto ver, Ramírez, S., "Igualdad como emancipación: Los derechos fundamentales de los pueblos indígenas", en Anuario de Derechos Humanos, Centro de Derechos Humanos, Universidad de Chile, 2007 , pp. 33 a 50.

59 Alto Comisionado de las Naciones Unidas para los Derechos Humanos. Derecho internacional de los derechos humanos, Oficina Regional para América Latina y el Caribe, Santiago de Chile, 2007, pp. 76 y 77.

${ }^{60}$ Cfr. Núnez, M., "Sobre la doctrina del margen de apreciación nacional...”, op. cit. p. 34. Para el caso colombiano Paola Acosta señala: “(...) dado que la doctrina del margen de apreciación ha sido concebida para concederle a los Estados un espacio de discrecionalidad en la determinación del contenido y alcance de sus obligaciones internacionales en materia de derechos humanos cuando ello no pone en riesgo la subsistencia misma de los individuos o sus condiciones más básicas de existencia no puede imaginarse su uso cuando se trata de graves situaciones de violencia o ante las violaciones más atroces como las estudiadas en los casos colombianos". Acosta, P., "Los casos colombianos ante el sistema interamericano...", op. cit, p. 187 (la cursiva es nuestra).

${ }^{61}$ Ibid., p. 43.

62 Ibid. 
propias del país y de las características particulares del hecho que se está conociendo, cuando la calidad institucional del país y la naturaleza de los hechos lo permitan, la CIDH puede disponer de distintas medidas de reparación en el cumplimiento de sentencias que hagan posible un fecundo "diálogo transjudicial". Se pueden buscar fórmulas inéditas que hagan posible establecer una interacción con las autoridades del país en cuestión, para avanzar en formas de reparación que encuentren una aceptación democrática y que por ello mismo tengan también mayores posibilidades de poder implementarse localmente.

\section{CONCLUSIONES}

Se ha entendido tradicionalmente que las sentencias dictadas por los tribunales internacionales solo constituyen fuentes auxiliares de derecho internacional y tienen efectos para las partes en litigio y respecto del caso que ha sido decidido.

La doctrina del control de convencionalidad postulada por la CIDH pretende instituir sus sentencias y opiniones consultivas como fuente de derecho interno en los países que han suscrito la Convención Americana de Derechos Humanos.

Bajo el control de convencionalidad las decisiones de la CIDH tienen aplicación directa en el derecho local y se sitúan dentro de aquello que no es "susceptible de ser decidido" por parte de las mayorías.

Para que el control de convencionalidad pueda afianzarse en un sistema interamericano de derechos humanos se precisaría una autorización constitucional explícita en los países miembros e incorporar de un modo diferenciado (según el grado de desarrollo institucional y el tipo de violación de que se trate) la doctrina del margen de apreciación nacional por parte de la CIDH.

La CIDH puede explorar distintas formas de diálogo interinstitucional mediante formas inéditas de reparación, de modo de hacer posible el cumplimiento de sus sentencias a nivel local.

\section{BIBLIOGRAFÍA}

Libros, revistas y artículos

Acosta Paola, "Los caso colombianos ante el sistema interamericano y el uso del margen de apreciación ¿ausencia justificada?, en Acosta, P, Núñez, M. (coord.), El Margen de Apreciación en el Sistema Interamericano de Derechos Humanos: Proyecciones Regionales y Nacionales, Instituto de Investigaciones Jurídicas de la UNAM, México, 2012.

Амвos, Kai, "Protección de Derechos Humanos e Internacionalización del Derecho Penal". En Internacionalización del Derecho Constitucional, constitucionalización del Derecho Internacional, Editorial Eudeba, Buenos Aires, 2012.

Barboza, Julio. Derecho Internacional Público, Víctor P. de Zavalía, 2008.

BARREIROS, Lucas, "El derecho internacional contemporáneo y el problema de la soberanía. Un intento de reconciliación". En Las fuentes del derecho internacional en la era de la globalización, Mónica Pinto (compiladora), Editorial Eudeba, 2009. 
BAYÓN, Juan Carlos, "Democracia y derechos: problemas de fundamentación del constitucionalismo", en El canon neoconstitucional, Miguel Carbonell y Leonardo García Jaramillo editores, Editorial Trotta, 2010.

Becerra, Manuel, La recepción del derecho internacional en el derecho interno, Universidad Nacional Autónoma de México, México D.F., 2006.

BAZÁn, Iván, "El Impacto de la Jurisprudencia de la Corte Interamericana de Derechos Humanos en el Perú. Una Evaluación Preliminar”, en Revista Ars Boni et Aequi, Universidad Bernardo O’Higgins, Vol. 7 Núm. 2, agosto 2011.

BIDART, Germán. "El panorama de los derechos humanos a fin de siglo" [en línea]. Biblioteca Jurídica Virtual. UNAM. Disponible en la web: http://www.bibliojuridica.org/libros/1/114/5.pdf

Bidart, Germán. El derecho de la Constitución y su fuerza normativa, México, IIJ- UNAM, 2003.

Cançado, Trindade, El Derecho Internacional de los Derechos Humanos en el siglo XXI, Editorial Jurídica de Chile, Santiago, 2006.

FuENTES, Ximena, "El derecho internacional y el derecho interno: definitivamente una pareja dispareja", Publicaciones del SELA Escuela de Derecho, Universidad de Yale, 2007.

Fuentes, Ximena, "La protección de la libertad de expresión en el sistema interamericano de derechos humanos y la promoción de la democracia”, en Revista de Derecho, Vol. XIII, Santiago, diciembre 2002.

Gordillo, Agustín, en Derechos Humanos, Fundación de Derechos Administrativos, Buenos Aires, 2005.

LinAres, Sebastián, La (i)legitimidad democrática del control judicial de la leyes, Marcial Pons, 2008.

LÜBBLE-WOLFF, Gertrude, "Justicia constitucional y justicia internacional: cooperaciones, conflictos y tensiones", en Internacionalización del Derecho Constitucional, constitucionalización del Derecho Internacional, Editorial Eudeba, Buenos Aires, 2012.

Llanos, Hugo, Teoría y Práctica del Derecho Internacional Público, Tomo I, Editorial Jurídica de Chile, Santiago, 2009.

MALARINO, Ezequiel, "Activismo judicial, punitivización y nacionalización. Tendencias antidemocráticas y antiliberales de la Corte Interamericana de Derechos Humanos", en Sistema Interamericano de Protección de los Derechos Humanos y Derecho Penal Internacional, Tomo II, Konrad Adenauer Stifung, 2011.

ManN, Lori, "El Tribunal Europeo y la Comisión Interamericana de Derechos Humanos: diferencias de metodología y sus implicaciones". Disponible en la web: http://www.womenslinkworldwide.org/pdf_pubs/es_pub_cuerpos3.pdf

Manili, P. "La recepción del derecho internacional de los derechos humanos por el derecho constitucional iberoamericano", en Internacionalización del Derecho Constitucional, constitucionalización del Derecho Internacional, Editorial Eudeba, Buenos Aires, 2012.

Mariño, Fernando, Derecho Internacional Público, Parte General, Trotta, Madrid, 1999.

Nash, Claudio, "Control de Convencionalidad. Precisiones conceptuales a la luz de la jurisprudencia de la Corte Interamericana de Derechos Humanos", en El diálogo transjudicial de los Tribunales Constitucionales entre sí y con las Cortes Internacionales de Derechos Humanos, en Nogueira. H. (coord.), Librotecnia, Santiago, 2012.

Nash, Claudio, Relación entre el Sistema Constitucional e Internacional en Materia de Derechos Humanos, Centro de Derechos Humanos, Universidad de Chile, 2012.

Neves, Marcelo, "Transcontitucionalismo, con especial referencia a la experiencia latinoamericana", en Internacionalización del Derecho Constitucional, constitucionalización del Derecho Internacional, Editorial Eudeba, Buenos Aires, 2012.

Nogueira, Humberto, "Aspectos fundamentales de la reforma constitucional de 2005 en materia de tratados internacionales", en La Constitución Reformada de 2005. Santiago, Centro de Estudios Constitucionales de Chile, Universidad de Talca, 2005. 
Ramírez, Silvina, "Igualdad como emancipación: Los derechos fundamentales de los pueblos indígenas", en Anuario de Derechos Humanos, Centro de Derechos Humanos, Universidad de Chile, 2007.

Requejo, Juan Luis, "Consideraciones en torno de las normas internacionales en el ordenamiento español”, en Revista Española de Derecho Constitucional, Centro de Estudios Constitucionales, España, 1992, volumen 44.

Rey, Ernesto, Control de convencionalidad de las leyes y derechos bumanos. Editorial Porrua, México 2008. Perotti, Alejandro, Habilitación constitucional para la integración comunitaria, Estudio sobre los Estados del Mercosur, TOMO I: Brasil y Paraguay, Montevideo 2004, Universidad Austral

SAGÜÉs, Néstor., "Obligaciones internacionales y control de convencionalidad", en Estudios Constitucionales, Centro de Estudios Constitucionales de Chile, Talca, 2010.

SAGÜÉs, Néstor, "Las relaciones entre los tribunales internacionales y los tribunales nacionales en materia de derechos humanos. Experiencias en Latinoamérica", en Revista Ius et Praxis, vol. 9, n. 1, Talca, 2003.

SAw, Malcom, International Law, VI Edición, Cambridge, 2008.

Sodero, Eduardo, "Precedente e internacionalización del derecho constitucional", en Internacionalización del Derecho Constitucional, constitucionalización del Derecho Internacional, Editorial Eudeba, Buenos Aires, 2012.

Von Bogdandy, Armin, "Del paradigma de la soberanía al paradigma del pluralismo normativo. Una nueva perspectiva (mirada) de la relación entre el derecho internacional y los ordenamientos jurídicos nacionales", en Internacionalización del Derecho Constitucional, constitucionalización del Derecho Internacional, Editorial Eudeba, Buenos Aires, 2012.

Waldron, Jeremy, Derecho y Desacuerdo, Maricial Pons, Madrid-Barcelona, 2005.

ZÚÑIga, Francisco, "Control de Convencionalidad y tribunales nacionales. Una aproximación crítica”, en Nogueira H. (coord.), El diálogo transjudicial de los Tribunales Constitucionales entre sí y con las Cortes Internacionales de Derechos Humanos, Librotecnia, 2012.

Sentencias Corte Interamericana de Derechos Humanos

CAso Almonacid Arellano vs. Chile. Sentencia de 26 de septiembre de 2006.

Caso Cabrera García y Montiel Flores vs. México. Sentencia de 26 de Noviembre de 2010.

Caso Gelman vs. Uruguay. Sentencia de 24 de febrero de 2010.

Caso Trabajadores Cesados del Congreso (Aguado Alfaro y otros) vs. Perú. Sentencia de 24 de noviembre de 2006.

Opinión Consultiva OC-16/99, de 1 de octubre de 1999, solicitada por los Estados Unidos Mexicanos.

Documentos

Normas de Procedimiento del Banco Mundial BP, 4.10 de julio de 2005.

Política Operacional Banco Mundial OP 4.10. 